\title{
Managing premature atherosclerosis in patients with chronic inflammatory diseases
}

\author{
Alexandra Legge MD, John G. Hanly MD
}

Cite as: CMAJ 2018 April 9;190:E430-9. doi: 10.1503/cmaj.170776

CMAJ Podcasts: author interview at https://soundcloud.com/cmajpodcasts/170776-rev

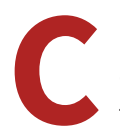

hronic inflammatory diseases, including rheumatoid arthritis, systemic lupus erythematosus, psoriatic arthritis and ankylosing spondylitis, are associated with increased risk of death relative to general population rates. ${ }^{1-4}$ This increased risk is largely attributable to atherosclerotic cardiovascular disease (CVD). ${ }^{2-5}$ Several studies have shown an increased risk of CVD in patients with chronic inflammatory diseases that is similar to the excess CVD risk conferred by diabetes mellitus ${ }^{6}-$ a disease for which there are well-established guidelines and practices for CVD prevention. However, CVD risk management strategies in patients with chronic inflammatory diseases remain suboptimal, and studies have shown that CVD is underrecognized and undertreated in this patient population. ${ }^{7,8}$ Furthermore, there is evidence that a lack of awareness among health care providers about the association between chronic inflammatory diseases and increased CVD risk may contribute to this disparity. ${ }^{9}$

Chronic inflammatory diseases are prevalent as a group of conditions. ${ }^{10}$ Optimal CVD prevention in patients with these diseases requires the active participation of multiple health care professionals, including rheumatologists, cardiologists, general internists and primary care practitioners. ${ }^{11,12}$ We summarize the evidence that shows increased cardiovascular morbidity and mortality among patients with chronic inflammatory diseases. We outline the underlying factors contributing to this excess CVD burden, highlight the challenges of CVD risk assessment in this population and propose an approach to CVD risk management in patients with chronic inflammatory diseases (our search strategy is in Box 1).

\section{What is the burden of cardiovascular disease in those with chronic inflammatory diseases?}

Premature atherosclerotic CVD is the leading cause of death among patients with chronic inflammatory diseases. ${ }^{2-5} \mathrm{Com}-$ pared with the general population, there is an increased risk of cardiovascular death among patients with rheumatoid arthritis, ${ }^{5}$ ankylosing spondylitis ${ }^{3}$ and systemic lupus erythematosus, ${ }^{2}$ whereas the results from studies involving patients with psoriatic arthritis are conflicting. ${ }^{4,13}$ In addition, there is also an increased

\section{KEY POINTS}

- Patients with chronic inflammatory diseases are at 1.5- to 2-fold increased risk of atherosclerotic cardiovascular disease.

- Both increased prevalence of traditional cardiovascular risk factors and disease-specific risk factors related to systemic inflammation contribute to this increased atherosclerotic risk.

- Cardiovascular disease and its risk factors are commonly underrecognized and undertreated among patients with chronic inflammatory diseases, further increasing the burden of atherosclerotic disease in this population.

- Strategies to reduce the risk of cardiovascular disease in patients with chronic inflammatory diseases include optimal control of disease activity, aggressive management of traditional cardiovascular risk factors and judicious use of antiinflammatory medications such as nonsteroidal anti-inflammatory drugs and corticosteroids.

risk of morbidity related to atherosclerotic CVD in this patient population. Patients with inflammatory joint diseases like rheumatoid arthritis, ankylosing spondylitis and psoriatic arthritis have a risk of myocardial infarction (MI) that is about $60 \%$ higher than in the general population. Systematic reviews have reported odds ratios (ORs) for incident $\mathrm{MI}$ of 1.68 (95\% confidence interval $[\mathrm{Cl}]$ 1.40-2.03) for patients with rheumatoid arthritis, ${ }^{14} 1.60$ (95\% Cl 1.32-1.93) for patients with ankylosing spondylitis ${ }^{15}$ and 1.57 (95\% Cl 1.08-2.27) for patients with psoriatic arthritis. ${ }^{13}$ For perspective, a Danish population-based cohort study found the incidence of $\mathrm{Ml}$ in patients with rheumatoid arthritis to be $70 \%$ higher than expected (incidence rate ratio [IRR] $1.7,95 \% \mathrm{Cl} 1.5-1.9)$. This was similar to the average risk of $\mathrm{Ml}$ among patients without rheumatoid arthritis who were 10 years older. ${ }^{6}$

The risk of incident CVD is even greater among patients with systemic inflammatory conditions such as systemic lupus erythematosus and systemic sclerosis, where the risk of MI and stroke are at least doubled compared with the general population. ${ }^{16,17}$ Furthermore, across all chronic inflammatory diseases, the relative risk of atherosclerotic events is greatest among young women, who would otherwise be at very low cardiovascular risk. ${ }^{6,16}$ Finally, 
not only is CVD more prevalent among patients with chronic inflammatory diseases, but the disease phenotype is severe with a poorer prognosis. ${ }^{7,18}$ Higher rates of sudden cardiac death ${ }^{7}$ and recurrent cardiovascular events ${ }^{18}$ were reported in recent observational studies that compared patients with rheumatoid arthritis to those without the disease. Understanding the factors that contribute to the excess CVD burden in this patient population is the first step in addressing this challenge.

\section{What factors contribute to this excess cardiovascular disease burden?}

\section{Systemic inflammation}

Traditional cardiac risk factors alone do not fully account for the excess CVD burden observed in chronic inflammatory diseases, ${ }^{19,20}$ suggesting that additional disease-specific factors are likely at play. Although the exact pathophysiologic mechanisms for this remain unknown, systemic inflammation appears to play a crucial role. ${ }^{21}$ Atherosclerotic CVD is recognized increasingly as a chronic inflammatory condition, ${ }^{22}$ with the immune system implicated in the formation, progression and stability of atherosclerotic lesions. $^{21}$

Inflammation appears to mediate the earliest stages of atherosclerosis, when the endothelial lining of arterial vessels becomes dysfunctional. ${ }^{21}$ Imaging studies have shown a greater degree of endothelial dysfunction, arterial stiffness and vascular inflammation among patients with chronic inflammatory diseases compared with the general population. ${ }^{23-25}$ These findings support the hypothesis that the systemic inflammation associated with chronic inflammatory diseases has direct vascular effects leading to accelerated atherosclerosis.

Systemic inflammation also promotes the rate of progression of atherosclerosis. Atherosclerotic plaques are more prevalent among patients with rheumatoid arthritis (OR 2.9, 95\% Cl 1.6$5.3)^{26}$ and systemic lupus erythematosus (OR 4.8, 95\% Cl 2.68.7), ${ }^{27}$ and, once established, growth of atherosclerotic plaque appears to be accelerated compared to patients without chronic inflammatory diseases. ${ }^{26}$ These findings persist even after adjustment for traditional cardiovascular risk factors. Furthermore,

\section{Box 1: Evidence used in this review}

We searched MEDLINE and PubMed (1980 to 2016) for our evidence review. Search terms included a combination of common terms used to describe atherosclerotic cardiovascular disease ("atherosclerosis," "cardiovascular disease," "coronary artery disease," "ischemic heart disease," "myocardial infarction," "acute coronary syndrome") and names of common chronic inflammatory diseases ("rheumatoid arthritis," "systemic lupus erythematosus," "psoriatic arthritis," "ankylosing spondylitis," "systemic sclerosis"). We also searched conference abstracts, as well as the reference lists of primary research studies, review articles and guidelines, to identify additional studies not found in the original search. We restricted our search to articles published in English. We considered randomized controlled trials, observational studies and relevant review articles in our evidence review. Suggestions for practice are based on information from multinational consensus guidelines. among patients with chronic inflammatory diseases, subclinical atherosclerosis correlates with measures of disease activity, inflammatory biomarkers and cumulative inflammatory burden, ${ }^{25-27}$ suggesting a dose-response relation between systemic inflammation and accelerated atherosclerosis.

As atherosclerotic plaques enlarge, they are at risk of rupture, leading to acute thrombotic events, such as MI or stroke. Patients with chronic inflammatory diseases have a more vulnerable, rupture-prone plaque phenotype. In rheumatoid arthritis, noninvasive imaging studies have shown an increased prevalence of "high-risk" atherosclerotic lesions compared to controls without rhematoid arthritis. ${ }^{26,28}$ These studies also reported an association between more active rheumatoid arthritis and a more ruptureprone plaque phenotype, ${ }^{26,28}$ suggesting a link between inflammatory burden and plaque vulnerability.

In summary, systemic inflammation promotes the formation, progression and rupture of atherosclerotic plaques, and contributes to the increased prevalence of atherosclerotic cardiovascular events observed among patients with chronic inflammatory diseases. Given the importance of inflammation in the pathogenesis of atherosclerotic CVD, it is not surprising that higher disease activity in chronic inflammatory diseases seems to confer higher cardiovascular risk. Cumulative inflammatory burden, the number and duration of disease flares, and elevated serum levels of inflammatory biomarkers are associated with increased risk of incident CVD and cardiovascular death among patients with chronic inflammatory diseases. ${ }^{29-32}$

\section{Traditional risk factors for cardiovascular disease}

Traditional risk factors for atherosclerosis, such as age, sex, family history of cardiovascular disease, dyslipidemia, hypertension, diabetes mellitus, obesity, cigarette smoking and physical inactivity are known to predict CVD risk in the general population. Although these factors do not fully explain the excess CVD burden observed in chronic inflammatory diseases, ${ }^{19,20,33}$ their contributions to the risk of atherosclerotic CVD are still important in this population. Of particular interest are traditional risk factors that are modifiable, because they provide a basis for effective strategies to reduce CVD risk in this population.

\section{Physical inactivity}

In the general population, physical activity is associated with lower cardiovascular risk, ${ }^{34}$ mediated in part through reductions in systemic inflammation. ${ }^{35}$ Recent studies conducted in rheumatoid arthritis and systemic lupus erythematosus suggested that aerobic exercise may have similar effects on cardiovascular health among patients with chronic inflammatory diseases. ${ }^{36,37}$ However, this patient population may experience disease-related barriers to performing physical activity, including joint inflammation and damage, systemic symptoms and treatment-related adverse effects. ${ }^{38,39}$ Several studies have confirmed that patients with chronic inflammatory diseases are indeed less physically active when compared with the general population. ${ }^{40-42}$ Effective interventions to improve habitual activity levels among patients with chronic inflammatory disease are required. 


\section{Cigarette smoking}

In addition to its role in promoting atherosclerotic CVD, cigarette smoking is also a strong environmental risk factor for the development of certain chronic inflammatory diseases. Two previous meta-analyses showed that current cigarette smokers are at increased risk of developing rheumatoid arthritis (OR $1.35,95 \% \mathrm{Cl} 1.17-2.55)^{43}$ and systemic lupus erythematosus (OR 1.50, 95\% Cl 1.09-2.08) ${ }^{44}$ compared to lifelong nonsmokers. Given the importance of cigarette smoking in the pathogenesis of these diseases, it is not surprising that the prevalence of smoking among patients with rheumatoid arthritis and systemic lupus erythematosus is increased compared with the general population..$^{32,45}$ This higher prevalence of cigarette smoking also likely contributes to the increased burden of atherosclerosis that is observed in these diseases. The link between cigarette smoking and the development of spondyloarthropathies, such as psoriatic arthritis and ankylosing spondylitis, is less clear. ${ }^{46,47}$ However, across all chronic inflammatory diseases, cigarette smoking is associated with adverse disease outcomes, including increased disease activity and poor treatment response. ${ }^{48-50}$ This serves as an additional mechanism by which smoking promotes systemic inflammation, accelerates atherosclerosis and increases CVD risk among patients with chronic inflammatory diseases.

\section{Hypertension}

Observational studies have reported increased prevalence of hypertension among patients with chronic inflammatory diseases compared to the general population..$^{40,47,51}$ Blood pressure in this patient population is highly variable over time, influenced by both systemic disease-related inflammation and its pharmacologic treatment. ${ }^{51,52}$ In a longitudinal observational study involving 1260 patients with systemic lupus erythematosus, disease activity was shown to be an independent predictor of hypertension. ${ }^{52}$ Specifically, higher disease activity scores for systemic lupus erythematosus were significantly associated with increases in both systolic and diastolic blood pressure $(p<$ 0.0001 for both associations). ${ }^{52}$ Finally, several medications commonly used in the treatment of chronic inflammatory diseases may also contribute to the development of hypertension, including nonsteroidal anti-inflammatory drugs (NSAIDs) and corticosteroids. ${ }^{51,52}$

\section{Insulin resistance and diabetes}

Similar to the general population, insulin resistance and type 2 diabetes mellitus are associated with increased CVD risk among patients with chronic inflammatory diseases. ${ }^{32,33}$ Systemic inflammation and the use of corticosteroids likely contribute to the development of insulin resistance and type 2 diabetes in this population. Both insulin resistance and type 2 diabetes are more common in patients with psoriatic arthritis ${ }^{53,54}$ and systemic lupus erythematosus $^{40}$ compared with the general population. However, no increased prevalence of either insulin resistance or type 2 diabetes has been reported among patients with ankylosing spondylitis. ${ }^{54}$ Although insulin resistance is more prevalent among patients with rheumatoid arthritis compared with the general population, ${ }^{55}$ results conflict with respect to rates of type 2 diabetes, ${ }^{45,55}$ which may be related to an underrecognition of diabetes mellitus in this patient population. ${ }^{56}$

\section{Obesity}

The prevalence of abdominal obesity is increased in patients with many chronic inflammatory diseases, including systemic lupus erythematosus, ${ }^{40}$ ankylosing spondylitis ${ }^{46}$ and psoriatic arthritis. ${ }^{47}$ For example, in a Norwegian study that compared 338 patients with psoriatic arthritis to 50468 controls, the rate of obesity was $40 \%$ higher among patients with psoriatic arthritis $(p<0.001) .{ }^{47}$ Among patients with systemic lupus erythematosus, ankylosing spondylitis and psoriatic arthritis, elevated body mass index (BMI) has been shown to be associated with increased disease activity, decreased physical function and increased CVD risk. ${ }^{32,40,46,47}$ Obesity is not clearly increased in patients with rheumatoid arthritis compared with the general population, ${ }^{55}$ but studies have described abnormalities in body composition among patients with rheumatoid arthritis, commonly referred to as rheumatoid cachexia. ${ }^{57}$ Compared to patients without rheumatoid arthritis, patients with the disease have decreased muscle mass and increased adiposity, and these changes are particularly prominent in the setting of active rheumatoid arthritis and high levels of systemic inflammation. ${ }^{57,58}$ As a result, inconsistent with other chronic inflammatory diseases and the general population, low BMI in patients with rheumatoid arthritis is associated with increased risk for atherosclerotic CVD. ${ }^{59}$ Thus, commonly used anthropometric measures, such as $\mathrm{BMI}$ and waist circumference, likely underestimate cardiovascular risk in this population. ${ }^{58}$

\section{Dyslipidemia}

In the general population, higher levels of total cholesterol and low-density lipoprotein cholesterol (LDL-C), as well as lower levels of high-density lipoprotein cholesterol (HDL-C), are associated with increased CVD risk. ${ }^{54,55}$ However, the association between serum lipid levels and CVD risk is more complicated among patients with chronic inflammatory diseases. Patients with active rheumatoid arthritis have lower total cholesterol and LDL-C levels compared with the general population but still demonstrate higher CVD risk. ${ }^{60,61}$ It has been suggested that this is due to even greater reductions in HDL-C that occur during rheumatoid arthritis flares, leading to a less favourable total cholesterol/HDL-C ratio and an overall more atherogenic lipid profile. ${ }^{54,55}$ Treatment with both conventional and biologic disease-modifying therapies to reduce rheumatoid arthritis disease activity and reverse the inflammatory state has been shown to increase all lipid components, but mostly HDL-C, leading to a less atherogenic total cholesterol/HDL-C ratio. ${ }^{62}$ Similar effects of disease activity and anti-inflammatory therapies on serum lipid levels have been found in patients with ankylosing spondylitis, psoriatic arthritis and systemic lupus erythematosus. ${ }^{32,63}$ Finally, both active rheumatoid arthritis and systemic lupus erythematosus have been associated with a proinflammatory form of HDL-C, which may also contribute to the development of atherosclerosis in patients with these conditions. ${ }^{64}$ 


\section{Underrecognition of cardiovascular disease and undertreatment of its risk factors}

Atherosclerotic CVD and its risk factors are underrecognized among patients with chronic inflammatory diseases, which likely contributes to the excess CVD burden in this population. For example, a population-based cohort study in the United States that compared 603 patients with rheumatoid arthritis to age- and sexmatched controls found that patients with the disease were significantly more likely to have an unrecognized MI (hazard ratio [HR] 2.13, 95\% Cl 1.13-4.03) or sudden cardiac death (HR 1.94, $95 \% \mathrm{Cl} 1.06-3.55){ }^{7}$ Although the exact reasons for this disparity are unknown, several possibilities have been identified. First, patients with chronic inflammatory diseases are more likely to present with atypical cardiovascular symptoms, ${ }^{7,65}$ which could lead to delays in the diagnosis of CVD. Second, chest discomfort among patients with chronic inflammatory diseases may be erroneously attributed to musculoskeletal causes, especially among younger women in whom the index of suspicion for atherosclerotic disease is typically low. ${ }^{65}$ Finally, musculoskeletal symptoms may restrict physical activity among patients with chronic inflammatory diseases, making them less likely to experience exertional angina ${ }^{7}$ and thus limiting opportunities for earlier CVD diagnosis. ${ }^{65}$

There is also evidence that a substantial number of patients with chronic inflammatory diseases have modifiable cardiovascular risk factors, such as hypertension, diabetes and dyslipidemia, that are either unrecognized by health care providers or are suboptimally treated compared with the general population. ${ }^{8,56,66} \mathrm{~A}$ cross-sectional study conducted in the Netherlands involving 327 patients with rheumatoid arthritis who had no prior history of CVD found that only $6 \%$ of patients with indications for lipid-lowering therapy were receiving statins, and, among those receiving statins, $86 \%$ were not meeting recommended treatment targets. ${ }^{8}$ Similar findings were reported for the undertreatment of hypertension. ${ }^{8}$ Finally, compared with the general population, studies have shown lower use of acute reperfusion therapy for the treatment of $\mathrm{MI},{ }^{67}$ as well as suboptimal use of pharmacotherapy for secondary CVD prevention, among patients with chronic inflammatory diseases. ${ }^{67,68} \mathrm{~A}$ populationbased retrospective study conducted in Denmark compared 877 patients with rheumatoid arthritis to 65230 patients without the disease after their first $\mathrm{Ml}$ and found that patients with rheumatoid arthritis had significantly lower rates of initiation of treatment with acetylsalicylic acid (OR $0.80,95 \% \mathrm{Cl}$ 0.67-0.96), $\beta$-blockers (OR 0.77, 95\% Cl 0.65-0.92) and statins (OR 0.69, $95 \% \mathrm{Cl} 0.58-0.82)$ at 30 days after discharge from hospital. ${ }^{68}$

Uncertainty regarding the respective roles of primary care providers, rheumatologists and other medical specialists in CVD risk management for patients with chronic inflammatory diseases likely contributes to the underrecognition and undertreatment of traditional cardiovascular risk factors in this population. ${ }^{9,11}$ Concerns about possible drug interactions with immunosuppressive therapies may also limit the use of pharmacotherapy to manage CVD risk factors among patients with chronic inflammatory diseases. Furthermore, lack of patient awareness of their increased CVD risk may also play an important role. ${ }^{9,69}$ A 2015 cross-sectional study involving 111 patients with rheumatoid arthritis found that, although $53 \%$ of these patients were estimated to be at high risk for CVD (defined as a 10-year risk of CVD events of $20 \%$ or more), only $3 \%$ thought they were at increased cardiovascular risk. ${ }^{69}$ This underrecognition of risk may contribute to lower patient adherence to provider recommendations about CVD risk reduction strategies. ${ }^{69}$

Lack of awareness among health care providers may also be a factor. In 2016, a qualitative study involving physicians who provide care to patients with rheumatoid arthritis found that about half of the primary care providers who were interviewed were unaware of the increased CVD risk in these patients. ${ }^{9}$ To optimize CVD risk management in patients with chronic inflammatory diseases, increasing both patient and health care provider awareness of the excess CVD burden associated with these conditions is crucial. Defining clear roles for all health care providers in the management of cardiovascular risk for patients with chronic inflammatory diseases and facilitating effective communication between providers are also critical.

\section{How should the risk of cardiovascular disease be assessed?}

We provide an approach to CVD risk assessment for patients with chronic inflammatory diseases in Box 2. Currently, the Canadian Cardiovascular Society recommends that risk assessment for CVD be performed every three to five years in all adult patients with chronic inflammatory diseases, regardless of patient age. ${ }^{70}$ Similar to guidelines for the general population, the society recommends using the Framingham Risk Score to estimate the 10-year risk of atherosclerotic cardiovascular events. ${ }^{70}$ However, as previously discussed, atherosclerotic risk in patients with chronic inflammatory diseases is less dependent on traditional risk factors; ${ }^{19,20,33}$ therefore, CVD risk prediction models that are designed for use in the general population, such as the Framingham Risk Score, substantially underestimate cardiovascular risk in patients with rheumatoid arthritis, ${ }^{77}$ psoriatic arthritis ${ }^{78}$ and systemic lupus erythematosus. ${ }^{20,71}$ Ideally, disease-specific risk prediction models that include both traditional and nontraditional risk factors should guide CVD risk management in patients with chronic inflammatory diseases, but the availability of wellvalidated disease-specific tools is limited.

To account for the higher atherosclerotic risk in patients with rheumatoid arthritis, the European League Against Rheumatism task force has suggested adapting algorithms for estimating CVD risk in the general population with a multiplication factor of 1.5 for all patients with rheumatoid arthritis. ${ }^{62}$ Using a similar approach, a recent study involving 905 women with systemic lupus erythematosus found that a modified version of the Framingham Risk Score, which used a multiplication factor of 2.0, more accurately predicted future coronary artery disease in this population (HR 4.37, 95\% Cl 2.39-7.98) compared with the classic Framingham Risk Score (HR 3.22, 95\% Cl 0.92-11.18). ${ }^{71}$ Although the ability of these modified scores to reclassify patients with chronic inflammatory diseases into more appropriate CVD risk categories is still unclear, ${ }^{79}$ this is the best-available, evidencebased approach to CVD risk estimation in this population until 
disease-specific tools can be developed. Of note, a 2014 populationbased study suggested that using carotid ultrasonography to screen for asymptomatic atherosclerotic plaques may provide a more accurate assessment of the atherosclerotic CVD risk in patients with rheumatoid arthritis compared with currently available risk prediction models. ${ }^{80}$ However, further research is required to determine the appropriate role for this tool in CVD risk assessment before it can be incorporated into routine screening for patients with chronic inflammatory diseases.

\section{What strategies should be used to reduce the risk of cardiovascular disease?}

Box 2 summarizes an approach to CVD risk management in patients with chronic inflammatory diseases. Broadly, current CVD risk reduction strategies in patients with chronic inflammatory diseases include optimal control of inflammatory disease activity, aggressive management of traditional cardiovascular risk factors and judicious use of anti-inflammatory drugs such as NSAIDs and corticosteroids.

\section{Optimal control of disease activity}

The cornerstone of therapy for patients with chronic inflammatory diseases is the use of disease-modifying antirheumatic drugs, which treat the underlying systemic inflammatory process to reduce disease symptoms, prevent or slow the rate of joint damage and improve health-related quality of life. There are several classes of disease-modifying antirheumatic drugs (Table 1), including conventional synthetic agents (e.g., methotrexate and hydroxychloroquine) and biologic therapies (e.g., tumour necrosis factor- $\alpha$ [TNF- $\alpha$ ] inhibitors). Given the known association between cumulative inflammatory burden and accelerated atherosclerosis, aggressive treatment of chronic inflammatory diseases with disease-modifying therapies to achieve tight and

Box 2: Proposed approach to atherosclerotic cardiovascular disease risk assessment and management for patients with chronic inflammatory diseases

\section{Overarching principles}

- All health care providers should be aware of the increased risk of cardiovascular disease (CVD) in patients with chronic inflammatory diseases, including rheumatoid arthritis, systemic lupus erythematosus, psoriatic arthritis and ankylosing spondylitis. ${ }^{11,12,62}$

- Cardiovascular disease risk assessment and management for patients with chronic inflammatory diseases should be addresed via a collaborative approach, with the active participation of patients, rheumatologists, primary care providers and other health care professionals. ${ }^{11,12}$

\section{Risk assessment for cardiovascular disease}

- Perform a comprehensive CVD risk assessment at least every three to five years..$^{62,70}$

- Reassess CVD risk whenever major changes in disease status or disease-modifying therapy occur. ${ }^{62}$

- Use CVD risk assessment tools currently recommended for the general population (e.g., the Framingham Risk Score) to estimate the 10-year CVD risk in patients with chronic inflammatory diseases. ${ }^{11,62,70}$

- Consider adapting 10-year risk estimates from CVD risk prediction models that have been recommended for the general population, such as the

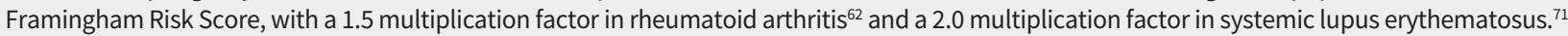

\section{Risk management for cardiovascular disease}

\section{Disease activity}

- Use appropriate disease-modifying antirheumatic therapy to control disease activity to reduce the atherosclerotic risk related to systemic inflammatory burden. ${ }^{32,62}$

\section{Traditional risk factors for cardiovascular disease}

- Provide lifestyle recommendations to all patients with chronic inflammatory diseases that emphasize the cardiovascular benefits of a healthy diet, regular physical activity, smoking cessation and maintenance of a healthy body weight. ${ }^{11,12,62}$

- Screen for and manage hypertension, ${ }^{72}$ dyslipidemia ${ }^{70}$ and diabetes mellitus ${ }^{73}$ in accordance with recommendations from national guidelines for the general population. ${ }^{11,12,62}$

- Ideally, measure serum lipid profile when chronic inflammatory diseases are stable or in remission. ${ }^{62,74}$

- In the presence of active inflammatory disease, consider using the total cholesterol/high-density lipoprotein cholesterol ratio to monitor for dyslipidemia. ${ }^{62,74}$

\section{Medication use}

- Use corticosteroids at the lowest effective dose for the shortest possible duration. ${ }^{12,62,75}$

- Taper corticosteroids once low disease activity or remission is reached. ${ }^{62}$

- In prolonged use, reassess the ongoing indication for corticosteroids regularly. ${ }^{62}$

- Discuss the risks and benefits of nonsteroidal anti-inflammatory drugs (NSAIDs) with all patients with chronic inflammatory diseases who are currently using NSAIDs or considering NSAID use..$^{12,62}$

- Use NSAIDs with caution in patients with rheumatoid arthritis, psoriatic arthritis and systemic lupus erythematosus, particularly if multiple CVD risk factors or documented atherosclerotic disease is present. ${ }^{62}$

- Nonsteroidal anti-inflammatory drugs remain a first-line therapy for patients with ankylosing spondylitis, ${ }^{76}$ and treatment decisions must be individualized. ${ }^{62}$ 
sustained control of disease activity is an important aspect of CVD risk reduction in this population.

Observational studies have shown a reduced risk of atherosclerotic CVD among patients with chronic inflammatory diseases who are treated with either conventional synthetic disease-modifying therapies, ${ }^{37,81,85,86}$ TNF- $\alpha$ inhibitors ${ }^{81,86-88}$ or both when compared to patients who did not receive treatment with these medications. In particular, a recent meta-analysis that included studies involving patients with rheumatoid arthritis reported similar reductions in the risk of CVD events with the use of methotrexate (relative risk [RR] $0.72,95 \% \mathrm{Cl} 0.57-0.91$ ) or TNF- $\alpha$ inhibitors (RR $0.70,95 \% \mathrm{Cl} 0.54-0.90) .{ }^{81}$ Other studies involving patients with rheumatoid arthritis and psoriatic arthritis have also shown improvements in insulin resistance, lipid profile and vascular function with the use of both conventional and biologic disease-modifying antirheumatic drugs. ${ }^{54}$ Although several observational studies involving patients with rheumatoid arthritis have reported greater CVD risk reduction in patients who were treated with TNF- $\alpha$ inhibitors compared to those treated with conventional synthetic therapies alone, ${ }^{81,87,88}$ other studies

Table 1: Commonly used pharmacotherapy options for chronic inflammatory diseases and their cardiovascular effects

\begin{tabular}{|c|c|c|c|c|}
\hline Medication class & $\begin{array}{l}\text { Examples of agents in } \\
\text { medication class }\end{array}$ & Relevant diseases & $\begin{array}{l}\text { Effects on risk factors for } \\
\text { cardiovascular disease }\end{array}$ & $\begin{array}{l}\text { Effects on outcomes for } \\
\text { cardiovascular disease }\end{array}$ \\
\hline $\begin{array}{l}\text { Nonsteroidal } \\
\text { anti-inflammatory } \\
\text { drugs }\end{array}$ & $\begin{array}{l}\text { - Diclofenac } \\
\text { - Ibuprofen } \\
\text { - Naproxen } \\
\text { - Meloxicam } \\
\text { - Celecoxib } \\
\text { - Rofecoxib (withdrawn) }\end{array}$ & $\begin{array}{l}\text { Primarily inflammatory } \\
\text { joint diseases (rheumatoid } \\
\text { arthritis, psoriatic arthritis, } \\
\text { ankylosing spondylitis) }\end{array}$ & $\begin{array}{l}\text { Mild anti-inflammatory } \\
\text { effects; increases blood } \\
\text { pressure, reduces renal } \\
\text { function and may increase } \\
\text { thromboembolic } \\
\text { complications. }\end{array}$ & $\begin{array}{l}\text { Most studies report } \\
\text { increased risk of CVD events } \\
\text { in patients with chronic } \\
\text { inflammatory diseases who } \\
\text { are receiving treatment } \\
\text { with NSAIDs, although risk } \\
\text { estimates vary between } \\
\text { agents. }{ }^{81} \text { Highest CVD risk } \\
\text { reported for rofecoxib and } \\
\text { diclofenac use; lowest risk } \\
\text { reported for naproxen. }{ }^{81,82}\end{array}$ \\
\hline Corticosteroids & $\begin{array}{l}\text { - Prednisone } \\
\text { - Prednisolone } \\
\text { - Methylprednisolone } \\
\text { - Dexamethasone }\end{array}$ & $\begin{array}{l}\text { Inflammatory joint } \\
\text { diseases (rheumatoid } \\
\text { arthritis, psoriatic arthritis, } \\
\text { ankylosing spondylitis) } \\
\text { and systemic lupus } \\
\text { erythematosus }\end{array}$ & $\begin{array}{l}\text { Potent anti-inflammatory } \\
\text { effects; weight gain; } \\
\text { increases in blood pressure, } \\
\text { serum triglyceride levels and } \\
\text { insulin resistance. }{ }^{83}\end{array}$ & $\begin{array}{l}\text { Dose- and duration- } \\
\text { dependent increase in CVD } \\
\text { risk in patients with } \\
\text { rheumatoid arthritis who } \\
\text { are receiving treatment } \\
\text { with steroids. }{ }^{75,84} \text { Short } \\
\text { courses could be beneficial } \\
\text { in highly active disease } \\
\text { (evidence lacking). }\end{array}$ \\
\hline $\begin{array}{l}\text { Conventional } \\
\text { synthetic disease- } \\
\text { modifying } \\
\text { antirheumatic drugs }\end{array}$ & $\begin{array}{l}\text { - Methotrexate } \\
\text { - Hydroxychloroquine } \\
\text { - Leflunomide }\end{array}$ & $\begin{array}{l}\text { Rheumatoid arthritis, } \\
\text { systemic lupus } \\
\text { erythematosus, psoriatic } \\
\text { arthritis }\end{array}$ & $\begin{array}{l}\text { Improvements in lipid } \\
\text { profile, insulin resistance, } \\
\text { physical activity and disease } \\
\text { activity. }\end{array}$ & $\begin{array}{l}\text { Decreased CVD risk } \\
\text { reported in observational } \\
\text { studies (strongest evidence } \\
\text { for methotrexate }{ }^{81,85} \text { and } \\
\text { hydroxychloroquine }{ }^{37,81} \text {. }\end{array}$ \\
\hline $\begin{array}{l}\text { Tumour necrosis } \\
\text { factor- } \alpha \text { inhibitors }\end{array}$ & $\begin{array}{l}\text { - Etanercept } \\
\text { - Adalimumab } \\
\text { - Infliximab } \\
\text { - Golimumab } \\
\text { - Certolizumab }\end{array}$ & $\begin{array}{l}\text { Inflammatory joint } \\
\text { diseases (rheumatoid } \\
\text { arthritis, psoriatic arthritis, } \\
\text { ankylosing spondylitis) }\end{array}$ & $\begin{array}{l}\text { Improvements in lipid } \\
\text { profile, insulin resistance } \\
\text { and disease activity. }{ }^{21,54}\end{array}$ & $\begin{array}{l}\text { Decreased CVD risk } \\
\text { reported in observational } \\
\text { studies. }^{81,86-88}\end{array}$ \\
\hline $\begin{array}{l}\text { B-cell depletion } \\
\text { therapies }\end{array}$ & Rituximab & $\begin{array}{l}\text { Rheumatoid arthritis, } \\
\text { systemic lupus } \\
\text { erythematosus (off label) }\end{array}$ & $\begin{array}{l}\text { Long-term treatment may } \\
\text { improve lipid profile. }{ }^{21}\end{array}$ & $\begin{array}{l}\text { Minimal data. Use with } \\
\text { caution in patients with } \\
\text { documented CVD. }{ }^{54}\end{array}$ \\
\hline $\begin{array}{l}\text { T-cell costimulation } \\
\text { inhibitors }\end{array}$ & Abatacept & Rheumatoid arthritis & $\begin{array}{l}\text { Improves disease activity; }{ }^{54} \\
\text { Impact on traditional risk } \\
\text { factors is unknown. }\end{array}$ & Unknown \\
\hline $\begin{array}{l}\text { Interleukin } \\
\text { (IL)-6-receptor } \\
\text { blocking monoclonal } \\
\text { antibodies }\end{array}$ & Tocilizumab & Rheumatoid arthritis & $\begin{array}{l}\text { Improves disease activity; } \\
\text { increases lipid levels } \\
\text { because of IL-6 inhibition. }{ }^{89,90}\end{array}$ & Unknown \\
\hline $\begin{array}{l}\text { Janus kinase } \\
\text { inhibitors }\end{array}$ & Tofacitinib & Rheumatoid arthritis & $\begin{array}{l}\text { Improves disease activity; } \\
\text { increases lipid levels } \\
\text { because of IL- } 6 \text { inhibition. }{ }^{90}\end{array}$ & Unknown \\
\hline
\end{tabular}


have not found this association. ${ }^{91}$ Thus, whether specific diseasemodifying antirheumatic drugs confer superior CVD risk reduction among patients with chronic inflammatory diseases requires further investigation. Given the apparent linear relation between lower disease activity and reduced atherosclerotic risk, studies are also ongoing to determine whether adopting more stringent targets for rheumatoid arthritis disease remission may provide additional cardiovascular benefits.

Medications with anti-interleukin-6 (anti-IL-6) effects, such as the biologic therapy, tocilizumab, and the targeted synthetic agent, tofacitinib, are being used increasingly for the treatment of rheumatoid arthritis (Table 1). Although these drugs are effective for reducing rheumatoid arthritis disease activity, ${ }^{89,90}$ they can also substantially alter serum lipid levels, ${ }^{89,90}$ leading to a more atherogenic lipid profile and potentially elevating CVD risk. Patients receiving these medications require regular monitoring of their lipid profile. Sustained elevations in serum lipids caused by these drugs can be managed successfully with statins and do not necessarily require that treatment with tocilizumab or tofacitinib be stopped unless lipid abnormalities are refractory to therapy. ${ }^{89,90}$

\section{Management of traditional risk factors for cardiovascular disease}

As in the general population, lifestyle modifications remain a critical aspect of CVD risk reduction in patients with chronic inflammatory diseases. All patients should be advised to stop smoking and given access to evidence-based resources for smoking cessation. Based on recommendations from the most recent Canadian guideline for physical activity for adults and older adults, patients with chronic inflammatory diseases should be encouraged to perform at least 150 minutes per week of moderate- to vigorous-intensity physical activity. ${ }^{92}$ Studies of structured exercise programs that involved patients with rheumatoid arthritis and systemic lupus erythematosus have shown beneficial cardiovascular effects, ${ }^{36,37,93}$ whereas, to date, no studies have reported major adverse effects of physical activity in patients with chronic inflammatory diseases. ${ }^{93}$

Although the "Mediterranean diet" has been associated with reduced CVD events in the general population, ${ }^{94}$ dietary interventions have not been studied adequately in patients with chronic inflammatory diseases. Therefore, based on the currently available evidence, a healthy diet that follows the recommendations of national guidelines could be suggested.

For traditional cardiovascular disease risk factors such as hypertension, diabetes mellitus and dyslipidemia, screening and management strategies for patients with chronic inflammatory diseases are similar to those used in the general population. ${ }^{62}$ Compared to individuals who do not have chronic inflammatory diseases, studies involving patients with rheumatoid arthritis and systemic lupus erythematosus have reported similar efficacy for statin, antihypertensive and antiplatelet drugs in optimizing cardiovascular risk factors and reducing the risk of atherosclerotic cardiovascular events. ${ }^{37,95} \mathrm{~A}$ randomized controlled trial of atorvastatin use ( $40 \mathrm{mg}$ daily) in 116 patients with rheumatoid arthritis also reported modest reductions in disease activity and inflammatory biomarkers with atorvastatin compared with pla- cebo, ${ }^{96}$ which suggests that statin therapy may reduce cardiovascular risk in patients with chronic inflammatory diseases via additional anti-inflammatory mechanisms. Although there are ongoing clinical trials that are investigating indications for broader use of these medications in this patient population, there is insufficient evidence currently to support intensified treatment goals or lower thresholds for starting pharmacotherapy in patients with chronic inflammatory diseases. Therefore, the assessment and management of hypertension, ${ }^{72}$ diabetes mellitus $^{73}$ and dyslipidemia ${ }^{70}$ in patients with chronic inflammatory diseases can follow the recommendations from current national guidelines for the general population.

There are a few special considerations when screening for dyslipidemia, because altered lipid metabolism in patients with chronic inflammatory diseases may affect the assessment of their lipid status. First, given that lipid levels tend to be lower in patients with active chronic inflammatory diseases despite higher CVD risk, the current approach to the measurement of serum lipids likely underestimates cardiovascular risk in these patients. ${ }^{74}$ Although serum LDL-C is commonly used as a reliable indicator for CVD risk in the general population, it appears to correlate poorly with the risk of CVD in patients with active chronic inflammatory diseases. ${ }^{32,55}$ In the context of active inflammatory disease, the total cholesterol/HDL-C ratio may be a more reliable marker of atherosclerotic CVD risk than individual lipid components. ${ }^{74}$ Therefore, the European League Against Rheumatism suggests using the total cholesterol/HDL-C ratio as the preferred lipid marker for CVD risk assessment in this population. ${ }^{62}$ Furthermore, because of the substantial variability in lipid levels related to changes in disease activity and anti-inflammatory therapies, lipid profiles in patients with chronic inflammatory diseases should be assessed during periods of low disease activity or remission, where possible. ${ }^{62}$

\section{Judicious use of other anti-inflammatory drugs}

Corticosteroids are potent anti-inflammatory agents with the potential to rapidly reduce systemic inflammation associated with chronic inflammatory diseases. They are commonly used as bridging therapy to control inflammation and improve disease-related symptoms while disease-modifying antirheumatic therapies are simultaneously escalated. However, corticosteroids are also known to have detrimental effects on several cardiovascular risk factors, including blood pressure, serum triglycerides and insulin resistance. ${ }^{83}$ A 2014 meta-analysis reported that corticosteroid use was associated with an increase in the risk of CVD events among patients with rheumatoid arthritis by about 50\% (RR 1.47, 95\% Cl 1.34-1.60). ${ }^{81}$ Furthermore, two 2014 observational studies involving patients with rheumatoid arthritis showed dose- and duration-dependent increases in CVD risk with corticosteroid use, which persisted after controlling for rheumatoid arthritis disease activity. ${ }^{75,84}$ However, although prolonged corticosteroid exposure is clearly deleterious for cardiovascular health in patients with chronic inflammatory diseases, it is possible that patients with highly active disease may derive overall cardiovascular benefits from short courses of corticosteroids to control systemic inflammation. For the treatment of active chronic inflammatory diseases, the lowest effective dose of corticosteroids 
should be prescribed for the shortest possible duration, ${ }^{12,62}$ with concurrent escalation of disease-modifying antirheumatic therapies in collaboration with a rheumatologist.

Nonsteroidal anti-inflammatory drugs, including both cyclooxygenase-2 (COX-2) inhibitors and nonselective NSAIDs, are commonly used in patients with chronic inflammatory diseases for symptomatic relief, particularly among patients with ankylosing spondylitis in whom NSAIDs are indicated as first-line pharmacotherapy. ${ }^{76}$ Although earlier data suggested significantly increased CVD risk with use of these medications, more recent evidence has shown that NSAIDs may be less deleterious for cardiovascular health in patients with chronic inflammatory diseases than previously reported. A 2014 meta-analysis found that NSAIDs may increase the CVD risk events overall in patients with rheumatoid arthritis (RR 1.18, 95\% Cl 1.01-1.38) ${ }^{81}$ However, this result was driven primarily by studies that evaluated the COX-2 inhibitor rofecoxib, which has been withdrawn from the market. Furthermore, a large observational study in Denmark that involved patients with rheumatoid arthritis showed that exposure to NSAIDs was associated with a significantly smaller increase in CVD risk (HR 1.22, 95\% $\mathrm{Cl}$ 1.09-1.37) than that observed for NSAID exposure in the general population (HR 1.51, 95\% Cl 1.36-1.66)..$^{82}$ When specific NSAIDs were evaluated, only rofecoxib (HR $1.57,95 \% \mathrm{Cl} 1.16-2.12)$ and diclofenac (HR 1.35, 95\% Cl 1.11-1.64) were associated with any increase in CVD risk among patients with rheumatoid arthritis. ${ }^{82}$ of note, in a recent randomized controlled trial that involved patients with osteoarthritis and rheumatoid arthritis, moderate-dose celecoxib (100 mg twice a day) was not inferior to either naproxen (HR 0.93, 95\% Cl 0.76-1.13) or ibuprofen (HR 0.85, 95\% Cl 0.70-1.04) with respect to the risk of major CVD events. ${ }^{97}$ However, current recommendations from the European League Against Rheumatism still suggest that all NSAIDs should be used cautiously in patients with chronic inflammatory diseases, particularly in the presence of hypertension, renal disease or multiple CVD risk factors. ${ }^{62}$ The safety of NSAID use in patients with chronic inflammatory diseases who have established atherosclerotic disease, including coronary artery disease, peripheral arterial disease or cerebrovascular disease, remains unclear. If NSAIDs are prescribed to a patient with a

\section{Box 3: Unanswered questions}

- What is the optimal cardiovascular disease (CVD) risk assessment strategy for patients with chronic inflammatory diseases? Is there a role for using carotid ultrasonography to screen for asymptomatic atherosclerotic plaques?

- Are specific classes of disease-modifying antirheumatic drugs associated with greater reductions in CVD risk?

- Are nonsteroidal anti-inflammatory drugs (NSAIDs) safe to use in patients with chronic inflammatory diseases who have documented atherosclerotic disease?

- What is the impact on CVD risk of short courses of corticosteroids used to treat patients with highly active chronic inflammatory diseases?

- With respect to hypertension and dyslipidemia, should there be more intensive treatment goals or lower thresholds for starting treatment in patients with chronic inflammatory diseases? chronic inflammatory disease, naproxen appears to have the most favourable profile for cardiovascular safety in this population and would be a reasonable first-line agent. ${ }^{81,82}$

\section{Conclusion}

The increased CVD risk that is observed among patients with chronic inflammatory diseases is related to both increased prevalence of traditional CVD risk factors and accelerated atherosclerosis secondary to systemic inflammation. Because CVD and its risk factors are commonly overlooked in patients with chronic inflammatory diseases, increased awareness among health care providers is crucial to reduce the excess CVD burden in this population. Future research effort is required to optimize CVD risk assessment and management strategies for these patients (Box 3).

\section{References}

1. Dadoun S, Zeboulon-Ktorza N, Combescure C, et al. Mortality in rheumatoid arthritis over the last fifty years: systematic review and meta-analysis. Joint Bone Spine 2013;80:29-33.

2. Yurkovich M, Vostretsova K, Chen W, et al. Overall and cause-specific mortality in patients with systemic lupus erythematosus: a meta-analysis of observational studies. Arthritis Care Res (Hoboken) 2014;66:608-16.

3. Zochling J, Braun J. Mortality in ankylosing spondylitis. Clin Exp Rheumatol 2008;26(Suppl 51):S80-4.

4. Gladman DD. Mortality in psoriatic arthritis. Clin Exp Rheumatol 2008;26(Suppl 51):S62-5.

5. Aviña-Zubieta JA, Choi HK, Sadatsafavi M, et al. Risk of cardiovascular mortality in patients with rheumatoid arthritis: a meta-analysis of observational studies. Arthritis Rheum 2008;59:1690-7.

6. Lindhardsen J, Ahlehoff $\mathrm{O}$, Gislason $\mathrm{GH}$, et al. The risk of myocardial infarction in rheumatoid arthritis and diabetes mellitus: a Danish nationwide cohort study. Ann Rheum Dis 2011;70:929-34.

7. Maradit-Kremers H, Crowson CS, Nicola PJ, et al. Increased unrecognized coronary heart disease and sudden deaths in rheumatoid arthritis: a population-based cohort study. Arthritis Rheum 2005;52:402-11.

8. van Breukelen-van der Stoep DF, van Zeben D, Klop B, et al. Marked underdiagnosis and undertreatment of hypertension and hypercholesterolaemia in rheumatoid arthritis. Rheumatology 2016;55:1210-6.

9. Bartels CM, Roberts TJ, Hansen KE, et al. Rheumatologist and primary care management of cardiovascular disease risk in rheumatoid arthritis: patient and provider perspectives. Arthritis Care Res (Hoboken) 2016;68:415-23.

10. Crowson CS, Matteson EL, Myasoedova E, et al. The lifetime risk of adult-onset rheumatoid arthritis and other inflammatory autoimmune rheumatic diseases. Arthritis Rheum 2011;63:633-9.

11. Barber CEH, Smith A, Esdaile JM, et al. Best practices for cardiovascular disease prevention in rheumatoid arthritis: a systematic review of guideline recommendations and quality indicators. Arthritis Care Res (Hoboken) 2015;67:169-79.

12. Barber CEH, Marshall DA, Alvarez N, et al. Development of cardiovascular quality indicators for rheumatoid arthritis: results from an international expert panel using a novel online process. J Rheumatol 2015;42:1548-55.

13. Horreau C, Pouplard C, Brenaut E, et al. Cardiovascular morbidity and mortality in psoriasis and psoriatic arthritis: a systematic literature review. $J$ Eur Acad Dermatol Venereol 2013;27(Suppl 3):12-29.

14. Avina-Zubieta JA, Thomas J, Sadatsafavi M, et al. Risk of incident cardiovascular events in patients with rheumatoid arthritis: a meta-analysis of observational studies. Ann Rheum Dis 2012;71:1524-9.

15. Mathieu S, Pereira B, Soubrier M. Cardiovascular events in ankylosing spondylitis: an updated meta-analysis. Semin Arthritis Rheum 2015;44:551-5.

16. Schoenfeld SR, Kasturi S, Costenbader KH. The epidemiology of atherosclerotic cardiovascular disease among patients with SLE: a systematic review. Semin Arthritis Rheum 2013;43:77-95. 
17. Ungprasert $P$, Charoenpong $P$, Ratanasrimetha $P$, et al. Risk of coronary artery disease in patients with systemic sclerosis: a systematic review and metaanalysis. Clin Rheumatol 2014;33:1099-104.

18. Douglas KMJ, Pace AV, Treharne GJ, et al. Excess recurrent cardiac events in rheumatoid arthritis patients with acute coronary syndrome. Ann Rheum Dis 2006;65:348-53.

19. del Rincón I, Williams K, Stern MP, et al. High incidence of cardiovascular events in a rheumatoid arthritis cohort not explained by traditional cardiac risk factors. Arthritis Rheum 2001;44:2737-45.

20. Esdaile JM, Abrahamowicz M, Grodzicky T, et al. Traditional Framingham risk factors fail to fully account for accelerated atherosclerosis in systemic lupus erythematosus. Arthritis Rheum 2001;44:2331-7.

21. Mason JC, Libby P. Cardiovascular disease in patients with chronic inflammation: mechanisms underlying premature cardiovascular events in rheumatologic conditions. Eur Heart J 2015;36:482-9c.

22. Ross R. Atherosclerosis - an inflammatory disease. N Engl J Med 1999;340: 115-26.

23. Sandoo A, Veldhuijzen van Zanten JJCS, Metsios GS, et al. Vascular function and morphology in rheumatoid arthritis: a systematic review. Rheumatology 2011;50:2125-39.

24. Wang D-G, Tang X-W, Fan Y, et al. Decreased flow-mediated dilatation in patients with systemic lupus erythematosus: a meta-analysis. Inflammation 2014;37:2067-75.

25. Shen J. Cumulative inflammatory burden is independently associated with increased arterial stiffness in patients with psoriatic arthritis: a prospective study. Arthritis Res Ther 2015;17:75.

26. Karpouzas GA, Malpeso J, Choi T-Y, et al. Prevalence, extent and composition of coronary plaque in patients with rheumatoid arthritis without symptoms or prior diagnosis of coronary artery disease. Ann Rheum Dis 2014;73:1797-804.

27. Roman MJ, Shanker B-A, Davis A, et al. Prevalence and correlates of accelerated atherosclerosis in systemic lupus erythematosus. N Engl J Med 2003;349: 2399-406.

28. Semb AG, Rollefstad S, Provan S, et al. Carotid plaque characteristics and disease activity in rheumatoid arthritis. J Rheumatol 2013;40:359-68.

29. Myasoedova E, Chandran A, Ilhan B, et al. The role of rheumatoid arthritis (RA) flare and cumulative burden of RA severity in the risk of cardiovascular disease. Ann Rheum Dis 2016;75:560-5.

30. Solomon DH, Reed GW, Kremer JM, et al. Disease activity in rheumatoid arthritis and the risk of cardiovascular events. Arthritis Rheumatol 2015;67:1449-55.

31. Eder L, Thavaneswaran A, Chandran V, et al. Increased burden of inflammation over time is associated with the extent of atherosclerotic plaques in patients with psoriatic arthritis. Ann Rheum Dis 2015;74:1830-5.

32. Tselios K, Sheane BJ, Gladman DD, et al. Optimal monitoring for coronary heart disease risk in patients with systemic lupus erythematosus: a systematic review. J Rheumatol 2016;43:54-65.

33. Gonzalez A, Kremers HM, Crowson CS, et al. Do cardiovascular risk factors confer the same risk for cardiovascular outcomes in rheumatoid arthritis patients as in non-rheumatoid arthritis patients? Ann Rheum Dis 2008;67:64-9.

34. Warburton DE, Charlesworth S, Ivey A, et al. A systematic review of the evidence for Canada's Physical Activity Guidelines for Adults. Int J Behav Nutr Phys Act 2010;7:39.

35. Kasapis C, Thompson PD. The effects of physical activity on serum C-reactive protein and inflammatory markers: a systematic review. J Am Coll Cardiol 2005; 45:1563-9.

36. Stavropoulos-Kalinoglou A, Metsios GS, Veldhuijzen van Zanten JJJCS, et al. Individualised aerobic and resistance exercise training improves cardiorespiratory fitness and reduces cardiovascular risk in patients with rheumatoid arthritis. Ann Rheum Dis 2013;72:1819-25.

37. Andrades C, Fuego C, Manrique-Arija S, et al. Management of cardiovascular risk in systemic lupus erythematosus: a systematic review. Lupus 2017;26:1407-19.

38. Mancuso CA, Perna M, Sargent AB, et al. Perceptions and measurements of physical activity in patients with systemic lupus erythematosus. Lupus 2011;20:231-42.

39. Veldhuijzen van Zanten JJCS, Rouse PC, Hale ED, et al. Perceived barriers, facilitators and benefits for regular physical activity and exercise in patients with rheumatoid arthritis: a review of the literature. Sports Med 2015;45: 1401-12.
40. Bruce IN, Urowitz MB, Gladman DD, et al. Risk factors for coronary heart disease in women with systemic lupus erythematosus: the Toronto Risk Factor Study. Arthritis Rheum 2003;48:3159-67.

41. O'Dwyer T, O'Shea F, Wilson F. Physical activity in spondyloarthritis: a systematic review. Rheumatol Int 2015;35:393-404.

42. Hernández-Hernandez V, Ferraz-Amaro I, Diaz-Gonzalez F. Influence of disease activity on the physical activity of rheumatoid arthritis patients. Rheumatology 2014;53:722-31.

43. Sugiyama D, Nishimura K, Tamaki K, et al. Impact of smoking as a risk factor for developing rheumatoid arthritis: a meta-analysis of observational studies. Ann Rheum Dis 2010;69:70-81.

44. Costenbader KH, Kim DJ, Peerzada J, et al. Cigarette smoking and the risk of systemic lupus erythematosus: a meta-analysis. Arthritis Rheum 2004;50: 849-57.

45. Boyer J-F, Gourraud P-A, Cantagrel A, et al. Traditional cardiovascular risk factors in rheumatoid arthritis: a meta-analysis. Joint Bone Spine 2011;78:179-83.

46. Papagoras C, Markatseli TE, Saougou I, et al. Cardiovascular risk profile in patients with spondyloarthritis. Joint Bone Spine 2014;81:57-63.

47. Gulati AM, Semb AG, Rollefstad S, et al. On the HUNT for cardiovascular risk factors and disease in patients with psoriatic arthritis: population-based data from the Nord-Trøndelag Health Study. Ann Rheum Dis 2016;75:819-24.

48. Doran MF, Brophy S, MacKay K, et al. Predictors of long term outcome in ankylosing spondylitis. J Rheumatol 2003;30:316-20.

49. Chang K, Yang S, Kim S, et al. Smoking and rheumatoid arthritis. Int J Mol Sci 2014; 15:22279-95.

50. Rodríguez Huerta MD, Trujillo-Martín MM, Rúa-Figueroa I, et al. Healthy lifestyle habits for patients with systemic lupus erythematosus: a systemic review. Semin Arthritis Rheum 2016;45:463-70.

51. Panoulas VF, Metsios GS, Pace AV, et al. Hypertension in rheumatoid arthritis. Rheumatology 2008;47:1286-98.

52. Nikpour M, Gladman DD, Ibañez D, et al. Variability over time and correlates of cholesterol and blood pressure in systemic lupus erythematosus: a longitudinal cohort study. Arthritis Res Ther 2010;12:R125.

53. Haroon M, Gallagher P, Heffernan E, et al. High prevalence of metabolic syndrome and of insulin resistance in psoriatic arthritis is associated with the severity of underlying disease. J Rheumatol 2014;41:1357-65.

54. Agca R, Heslinga SC, van Halm VP, et al. Atherosclerotic cardiovascular disease in patients with chronic inflammatory joint disorders. Heart 2016;102:790-5.

55. Liao KP, Solomon DH. Traditional cardiovascular risk factors, inflammation and cardiovascular risk in rheumatoid arthritis. Rheumatology 2013;52:45-52.

56. Ursini F, Russo E, D'Angelo S, et al. Prevalence of undiagnosed diabetes in rheumatoid arthritis. Medicine 2016;95:e2552-7.

57. Giles JT, Allison M, Blumenthal RS, et al. Abdominal adiposity in rheumatoid arthritis: Association with cardiometabolic risk factors and disease characteristics. Arthritis Rheum 2010;62:3173-82.

58. Stavropoulos-Kalinoglou A, Metsios GS, Koutedakis Y, et al. Obesity in rheumatoid arthritis. Rheumatology 2011;50:450-62.

59. Summers GD, Metsios GS, Stavropoulos-Kalinoglou A, et al. Rheumatoid cachexia and cardiovascular disease. Nat Rev Rheumatol 2010;6:445-51.

60. Myasoedova E, Crowson CS, Kremers HM, et al. Lipid paradox in rheumatoid arthritis: the impact of serum lipid measures and systemic inflammation on the risk of cardiovascular disease. Ann Rheum Dis 2011;70:482-7.

61. Liao KP, Cai T, Gainer VS, et al. Lipid and lipoprotein levels and trend in rheumatoid arthritis compared to the general population. Arthritis Care Res (Hoboken) 2013;65:2046-50.

62. Agca R, Heslinga SC, Rollefstad S, et al. EULAR recommendations for cardiovascular disease risk management in patients with rheumatoid arthritis and other forms of inflammatory joint disorders: 2015/2016 update. Ann Rheum Dis 2017;76:17-28.

63. Peters MJ, van der Horst-Bruinsma IE, Dijkmans BA, et al. Cardiovascular risk profile of patients with spondylarthropathies, particularly ankylosing spondylitis and psoriatic arthritis. Semin Arthritis Rheum 2004;34:585-92.

64. McMahon M, Grossman J, FitzGerald J, et al. Proinflammatory high-density lipoprotein as a biomarker for atherosclerosis in patients with systemic lupus erythematosus and rheumatoid arthritis. Arthritis Rheum 2006;54:2541-9.

65. Hollan I, Dessein PH, Ronda N, et al. Prevention of cardiovascular disease in rheumatoid arthritis. Autoimmun Rev 2015;14:952-69. 
66. Keeling SO, Teo M, Fung D. Lack of cardiovascular risk assessment in inflammatory arthritis and systemic lupus erythematosus patients at a tertiary care center. Clin Rheumatol 2011;30:1311-7.

67. Van Doornum S, Brand C, Sundararajan V, et al. Rheumatoid arthritis patients receive less frequent acute reperfusion and secondary prevention therapy after myocardial infarction compared with the general population. Arthritis Res Ther 2010;12:R183.

68. Lindhardsen J, Ahlehoff O, Gislason GH, et al. Initiation and adherence to secondary prevention pharmacotherapy after myocardial infarction in patients with rheumatoid arthritis: a nationwide cohort study. Ann Rheum Dis 2012;71:1496-501.

69. van Breukelen-van der Stoep DF, Zijlmans J, van Zeben D, et al. Adherence to cardiovascular prevention strategies in patients with rheumatoid arthritis. Scand J Rheumatol 2015;44:443-8.

70. Anderson TJ, Grégoire J, Hegele RA, et al. 2012 update of the Canadian Cardiovascular Society guidelines for the diagnosis and treatment of dyslipidemia for the prevention of cardiovascular disease in the adult. Can J Cardiol 2013;29:151-67.

71. Urowitz MB, Ibañez D, Su J, et al. Modified Framingham Risk Factor Score for systemic lupus erythematosus. J Rheumatol 2016;43:875-9.

72. Leung AA, Nerenburg K, Daskalopoulou SS, et al. Hypertension Canada's 2016 Canadian Hypertension Education Program guidelines for blood pressure measurement, diagnosis, assessment of risk, prevention, and treatment of hypertension. Can J Cardiol 2016;32:569-88.

73. Ekoé JM, Punthakee Z, Ransom T, et al. Canadian Diabetes Association Clinical Practice Guidelines Expert Committee. Screening for type 1 and type 2 diabetes. Can J Diabetes 2013;37(Suppl1):S12-5.

74. Toms TE, Panoulas VF, Douglas KMJ, et al. Are lipid ratios less susceptible to change with systemic inflammation than individual lipid components in patients with rheumatoid arthritis? Angiology 2011;62:167-75.

75. del Rincón I, Battafarano DF, Restrepo JF, et al. Glucocorticoid dose thresholds associated with all-cause and cardiovascular mortality in rheumatoid arthritis. Arthritis Rheumatol 2014;66:264-72.

76. Ward MM, Deodhar A, Akl EA, et al. American College of Rheumatology/ Spondylitis Association of America/Spondyloarthritis Research and Treatment Network 2015 recommendations for the treatment of ankylosing spondylitis and nonradiographic axial spondyloarthritis. Arthritis Rheumatol 2016;68:282-98.

77. Arts EEA, Popa C, Broeder Den AA, et al. Performance of four current risk algorithms in predicting cardiovascular events in patients with early rheumatoid arthritis. Ann Rheum Dis 2015;74:668-74.

78. Eder L, Chandran V, Gladman DD. The Framingham Risk Score underestimates the extent of subclinical atherosclerosis in patients with psoriatic disease. Ann Rheum Dis 2014;73:1990-6.

79. Arts EEA, Popa CD, Broeder Den AA, et al. Prediction of cardiovascular risk in rheumatoid arthritis: performance of original and adapted SCORE algorithms. Ann Rheum Dis 2016;75:674-80.

80. Corrales A, González-Juanatey C, Peiró ME, et al. Carotid ultrasound is useful for the cardiovascular risk stratification of patients with rheumatoid arthritis: results of a population-based study. Ann Rheum Dis 2014;73:722-7.

81. Roubille C, Richer V, Starnino T, et al. The effects of tumour necrosis factor inhibitors, methotrexate, non-steroidal anti-inflammatory drugs and corticosteroids on cardiovascular events in rheumatoid arthritis, psoriasis and psoriatic arthritis: a systematic review and meta-analysis. Ann Rheum Dis 2015;74:480-9.

82. Lindhardsen J, Gislason GH, Jacobsen S, et al. Non-steroidal antiinflammatory drugs and risk of cardiovascular disease in patients with rheumatoid arthritis: a nationwide cohort study. Ann Rheum Dis 2014;73: 1515-21.

83. Walker BR. Glucocorticoids and cardiovascular disease. Eur J Endocrinol 2007;157:545-59.

84. Ajeganova S, Svensson B, Hafström I; BARFOT Study Group. Low-dose prednisolone treatment of early rheumatoid arthritis and late cardiovascular outcome and survival: 10-year follow-up of a 2-year randomised trial. BMJ Open 2014;4:e004259.

85. Westlake SL, Colebatch AN, Baird J, et al. The effect of methotrexate on cardiovascular disease in patients with rheumatoid arthritis: a systematic literature review. Rheumatology 2010;49:295-307.

86. Ahlehoff O, Skov L, Gislason G, et al. Cardiovascular outcomes and systemic anti-inflammatory drugs in patients with severe psoriasis: 5-year follow-up of a Danish nationwide cohort. J Eur Acad Dermatol Venereol 2015;29:1128-34.

87. Low ASL, Symmons DPM, Lunt M, et al.; British Society for Rheumatology Biologics Register for Rheumatoid Arthritis (BSRBR-RA) and the BSRBR Control Centre Consortium. Relationship between exposure to tumour necrosis factor inhibitor therapy and incidence and severity of myocardial infarction in patients with rheumatoid arthritis. Ann Rheum Dis 2017;76:654-60.

88. Solomon DH, Curtis JR, Saag KG, et al. Cardiovascular risk in rheumatoid arthritis: comparing TNF- $\alpha$ blockade with nonbiologic DMARDs. Am J Med 2013;126:730.e9-17.

89. Navarro G, Taroumian S, Barroso N, et al. Tocilizumab in rheumatoid arthritis: a meta-analysis of efficacy and selected clinical conundrums. Semin Arthritis Rheum 2014;43:458-69.

90. Souto A, Salgado E, Maneiro JR, et al. Lipid profile changes in patients with chronic inflammatory arthritis treated with biologic agents and tofacitinib in randomized clinical trials: a systematic review and meta-analysis. Arthritis Rheumatol 2015;67:117-27.

91. Ljung L, Simard JF, Jacobsson L, et al.; Anti-Rheumatic Therapy in Sweden (ARTIS) Study Group. Treatment with tumor necrosis factor inhibitors and the risk of acute coronary syndromes in early rheumatoid arthritis. Arthritis Rheum 2012;64:42-52.

92. Tremblay MS, Warburton DER, Janssen I, et al. New Canadian physical activity guidelines. Appl Physiol Nutr Metab 2011;36:36-46.

93. Lemmey AB, Marcora SM, Chester K, et al. Effects of high-intensity resistance training in patients with rheumatoid arthritis: a randomized controlled trial. Arthritis Rheum 2009;61:1726-34.

94. Estruch R, Ros E, Salas-Salvad J, et al. Primary prevention of cardiovascular disease with a Mediterranean diet. N Engl J Med 2013;368:1279-90.

95. Semb AG, Kvien TK, DeMicco DA, et al. Effect of intensive lipid-lowering therapy on cardiovascular outcome in patients with and those without inflammatory joint disease. Arthritis Rheum 2012;64:2836-46.

96. McCarey DW, Mclnnes IB, Madhok R, et al. Trial of atorvastatin in rheumatoid arthritis (TARA): double-blind, randomised placebo-controlled trial. Lancet 2004;363:2015-21.

97. Nissen SE, Yeomans ND, Solomon DH, et al. Cardiovascular safety of celecoxib, naproxen, or ibuprofen for arthritis. N Engl J Med 2016;375:2519-29.

\section{Competing interests: None declared.}

This article has been peer reviewed.

Affiliations: Department of Medicine (Legge); Division of Rheumatology, Department of Medicine, and Department of Pathology (Hanly), Dalhousie University and Queen Elizabeth II Health Sciences Centre, Halifax, NS
Contributors: Both of the authors contributed to the conception and design of the review. Alexandra Legge performed the original literature search and drafted the first version of the manuscript. Both of the authors reviewed the manuscript critically for important intellectual content, gave final approval of the version to be published and agreed to be accountable for all aspects of the work.

Correspondence to: John G. Hanly, john.hanly@nshealth.ca 